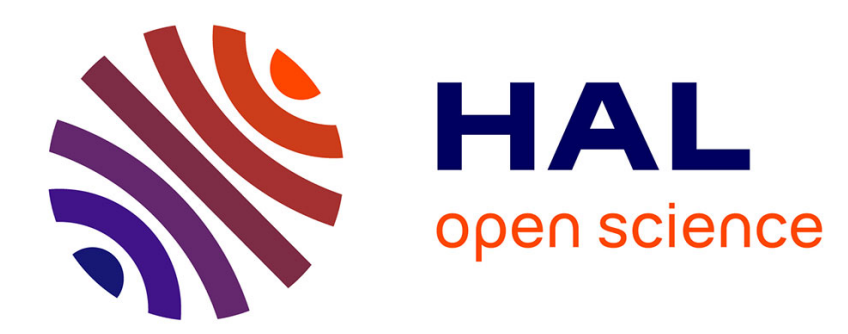

\title{
THE ENERGY GAP OF SUPERCONDUCTING (SN)x
}

G. Binnig, H. Hoenig

\section{To cite this version:}

G. Binnig, H. Hoenig. THE ENERGY GAP OF SUPERCONDUCTING (SN)x. Journal de Physique Colloques, 1978, 39 (C6), pp.C6-441-C6-443. 10.1051/jphyscol:19786198 · jpa-00217615

\section{HAL Id: jpa-00217615 https://hal.science/jpa-00217615}

Submitted on 1 Jan 1978

HAL is a multi-disciplinary open access archive for the deposit and dissemination of scientific research documents, whether they are published or not. The documents may come from teaching and research institutions in France or abroad, or from public or private research centers.
L'archive ouverte pluridisciplinaire HAL, est destinée au dépôt et à la diffusion de documents scientifiques de niveau recherche, publiés ou non, émanant des établissements d'enseignement et de recherche français ou étrangers, des laboratoires publics ou privés. 


\title{
THE ENERGY GAP OF SUPERCONDUCTING $(S N)_{x}{ }^{*}$
}

\author{
G. Binnig and H.E. Hoenig
}

Physikalisches Institut der Universität Frankfurt, Germany

\begin{abstract}
Résumé.- Nous présentons des expériences d'effet tunnel entre (SN) et l'indium pour différents cristaux de (SN). Nous avons mesuré une grande valeur de la bande d'énergie interdite et nous prêsentonš des indications allant dans le sens d'une forte anisotropie de cette bande d'énergie interdite.
\end{abstract}

Abstract.- We report on experiments of tunneling from bulk indium metal into (SN) $\mathrm{X}$ crystals and of tunneling between different $(\mathrm{SN}) \mathrm{x}$ crystals. We have measured a surprisingly large energy gap and we have found indications for a strong anisotropy of the gap.

Polymeric sulfur nitride has become known as an extremely anisotropic superconductor /1-3/. The intrinsic anisotropy from the electronic bandstructure /4/ shows 1-dimensional features but is sufficiently 3-dimensional to allow superconductivity. The important extrinsic reason for the anisotropy of crystalline (SN) $x$ is the macroscopic defect structure $/ 3 /$. The directed polymer growth creates a fibrous substructure of more or less separated single crystals of about $200 \AA$ in diameter which we will call fibers. The superconducting order parameter seems to be confined to sections of these fibers some hundred $\AA$ long which are weakly coupled, the confinement giving rise to pronounced zeroand onedimensional fluctuations /5/.

The question arises if the superconducting order parameter or the gap of $(\mathrm{SN})_{x}$ is anomalous. with respect to its absolute value and its angular dependence for the intrinsic and (or) extrinsic reasons mentioned above.

For the preparation of tunneling junctions three different methods have been used. All of them had in common that four $\mathrm{V}$-shaped pieces of freshly cut indium metal were prepared in a row. (SN) $x$ needles of an approximate length of $5 \mathrm{~mm}$ and about $50 \mu \mathrm{m}$ diameter, consisting of many elementary fibers, were cleaved from larger crystals (supplied by L. Pintschovius) $/ 6 /$ just before applying the contacts or taken as grown. An $(\mathrm{SN})_{\mathrm{x}}$ needle was put across the indium hooks which were then gently closed. In this way four tunneling contacts were formed.

\footnotetext{
* Work supported by Deutsche Forschungsgemeinschaf $t /$ SFB 65 .
}

PROCEDURE A : One of these tunneling contacts was used as tunneling junction with two leads (I and V) the others served as interchangeable current- and voltage contacts for the $(\mathrm{SN})_{X}$ part of the junction. Procedure A gave a differential tunneling resistance $\rho(V)$ which did not deviate noticeably from the inverse quasiparticle excitation spectrum of superconducting indium. The ratio $\rho(0) / \rho(10 \mathrm{mV})$ was a large as 200 . But no indications for a change in the tunneling resistance below $300 \mathrm{mK}$ due to the superconductivity of $(\mathrm{SN})_{X}$ were detected. Applying procedure A the turneling depth might be too small or the predominant tunneling direction might be transverse to the fiber and in that direction the gap could be too small to be detectable.

PROCEDURE B. - Additionally to procedure A the tunnel junction was cut through with a scalpel. This way the (SN) $x$ needle was cut through also and covered at the cut with solid indium using the solid itself for protection against the access of air. Procedure B produced tunneling characteristics indicating the superconductivity of $(\mathrm{SN})_{x}$. Representative results at $50 \mathrm{mK}$ are given in Figure 1. The relative and absolute size of the peaks of Figure 1 varied between samples, also did the general shape of the characteristics. But all junctions had the following properties in common : (1) A doubling of the indium gap peak at $\pm 600 \mu \mathrm{V}$ was observed. The separation of both peaks was $80 \pm 10 \mu \mathrm{V}$.

(2) The peak at higher vo1tage vanished by app1ying a magnetic field smaller than $20 \mathrm{G}$. The junction was magnetically shielded by the superconducting indium. 


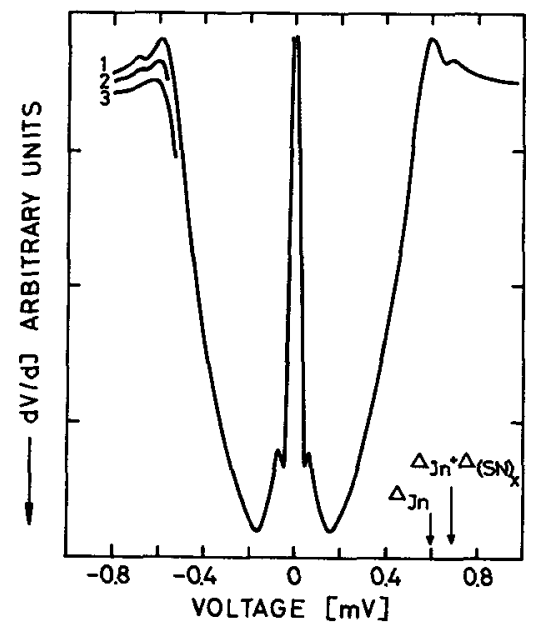

Fig. 1 : Differential tunneling resistance of a (SN) $x$ - indium tunnel junction versus voltage across the junction for three different temperatures (1) $50 \mathrm{mk}$, (2) $100 \mathrm{mK}$, and (3) $300 \mathrm{mK}$ (procedure B)

(3) The double structure appeared at a temperature of $120 \pm 30 \mathrm{mK}$ and became more distinct at lower temperatures.

(4) In all cases a Josephson current up to $60 \mu \mathrm{A}$ was measured. In the $\mathrm{dV} / \mathrm{dI}$ characteristics (figure 1) it appeared as a sharp peak at zero voltage. The Josephson current could be suppressed by applying a magnetic field smaller than $30 \mathrm{G}$ (shielded by indium). From the temperature dependence of the critical Josephson current a transition temperature $\mathrm{T}=275 \pm 20 \mathrm{mK}$ was obtained.

(5) For temperatures below $T_{c}$ additional conductivity was measured up to $\Delta(\mathrm{In})$ which filled the indium gap and reduced the ratio $p(\approx 0) / \rho(10 \mathrm{mV})$ to values smaller than ten. From the dependence of the $I(V)$ characteristics on temperature and magnetic field and from their reproducibility we conclude that the double peak of procedure $B$ cannot result from a gap anisntropy of indium or from a proximity effect of a thin normal layer between tunneling barrier and indium metal.

PRODEDURE C.- First the $(\mathrm{SN}) \mathrm{x}$ needle was prepared as in. A. Then the needle was broken in the middle between the four indium blocks and put together immediately. Procedure $\mathrm{C}$ gave a tunneling characteristic as shown in Figure 2a. A slowly varying zero bias anomaly has been subtracted for clarity. The essential results are a step at $90 \mu \mathrm{V}$ and a

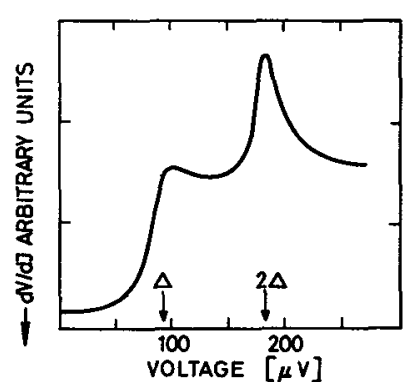

Fig.2a : Differential tunneling resistance of $a(\mathrm{SN})_{\mathrm{x}}-(\mathrm{SN}) \mathrm{x}$ tunnel junction at $50 \mathrm{mk}$ (prodedure $\mathrm{C}$ ).

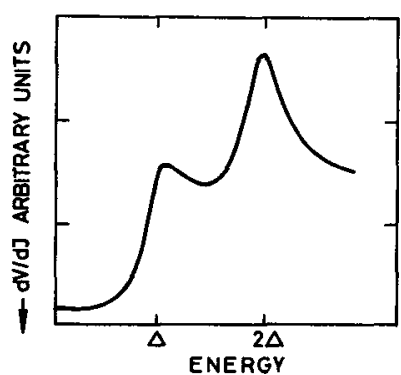

In the cases $\mathrm{B}$ and $\mathrm{C}$ fibers are broken and we have to expect additional tunneling contacts at endfaces with tunneling direction parallel to the fiber. If in thiscase the tunneling depth samples superconducting regions or directions in (SN) we have to consider parallel circuits of a variety of tunneling junctions. In the case of procedure $B$ we have to expect $\mathrm{S}-\mathrm{N}$ and $\mathrm{S}-\mathrm{S}$ junctions in parallel in the case $C$ we have to consider $S-N, S-S$ and $N-N$ junctions in parallel as well where $S$ and $N$ denote superconducting and normal contacts respectively, $\left.{ }^{(\mathrm{SN}}\right)_{\mathrm{X}}$ being normal because of position or direction. All features of this model are observed simultaneous1y. A model calculation for procedure $C$ gives a good fit to the measured differential resistance (Figure $2 \mathrm{~b}$ ). Within the model we obtain the rather large value of $\Delta(\mathrm{SN})_{\mathrm{X}}=80 \pm 10 \mu \mathrm{eV}$ and $2 \Delta / k_{B} T_{C}=6.5 \pm 1$. Since strong coupling seems to be ruled out /4/ possible explanations are i) 1-dimensional fluctuations which reduce $T_{c}$ keeping $\Delta(0)$ unchanged or ii) intrinsic anisotropy (Fermi surface, phonon dispersion) and- or iii) extrinsic anisotropy from a transverse proximity effect. The latter two reasons imply $\Delta_{=}=$ $80 \pm 10 \mu \mathrm{eV}$ for tunneling parallel to the fiber axis, $\Delta \perp$ being too small to be observable. 


\section{References}

/1/ Greene, R.L. Street, G.B. and Suter, L.J., Phys. Rev, Letters 34 (1975) 577.

/2/ Geserich, H.P. and Pintschovius, L., Advances in Solid State Physics, Vol. XVI, ed. by Treusch, J.,Vieweg, Braunschweig, Germany (1976) p.65.

/3/ Street, G.B., Greene, R.L. and IBM J. Res. Develop. 21 (1977) 99.

/4/ Chelikowsky, J.R., Schlüter and M., Cohen, M.L., Phys. stat. sol. (b) 82 (1977) 357 and references therein.

/5/ Civiak, R.J., Elbaum, C., Nichols, L.F., Kao, H.I. and Labes, M.M., Phys. Rev. B 14, (1976) 5413 .

/6/ Pintschovius, L., Wende1, H. and Currat, R., Proc. Int. Conf. Lattice Dynamics, Sept. 1977, Paris, edited by Balkanski, M. Flamarion, Paris (1978). 